The Preparation of Programs for an Electronic Digital Computer

With Special Reference to the EDSAC and the use of a Library of Subroutines. By Maurice V. Wilkes, David J. Wheeler and Stanley Gill. Pp. xiii +170. (Cambridge, Mass.: Addison-Wesley Press, Inc., 1951.) 5 dollars.

7 HIS is the first published account of all the details necessary for the preparation of a mathematical problem for solution by the University of Cambridge computer EDSAC.

It is in three parts, bound in one volume. The first part begins with a chapter introducing the basic features of an electronic digital computer in so far as they concern the user, giving the 'order code' and the method of decimal to binary conversion and deconversion. Subsequent chapters describe the input of orders, the use of previously prepared and checked programmes for subsidiary calculations encountered in the course of the problem (known as 'subroutines'), the means adopted to eliminate errors of all kinds, and the use of the EDSAC organization as a whole. The first part ends with several examples worked in detail, including the evaluation of a definite integral, the integration of an ordinary differential equation, and Graeffe's root-squaring process for the solution of algebraic equations.

Part 2 gives the user's specifications of nearly all the subroutines already compiled in the EDSAC 'library', and Part 3 describes the actual sequences of orders in certain selected subroutines.

The subject-matter is concisely yet very clearly presented, with notably few misprints, in a slim and stoutly bound volume. M. WOODGER

Photometric Atlas of the Near Infra-Red Solar Spectrum $\lambda 8465$ to $\lambda 25,242$

By Orren C. Mohler, A. Keith Pierce, Robert R. McMath and Leo Goldberg. Pp. iv $+7+234$ plates. (Ann Arbor: University of Michigan Press, 1950.) 4 dollars.

7 HIS is the first of a series of projected publica-

tions dealing with solar radiation in the near infra-red region. A companion volume will list the wave-lengths, equivalent widths and identifications of the features given here as intensity tracings, and future atlases will show laboratory spectra of such telluric molecules as $\mathrm{H}_{2} \mathrm{O}, \mathrm{CO}_{2}, \mathrm{CH}_{4}$ and $\mathrm{N}_{2} \mathrm{O}$ in this region. For the present work, the McMath-Hulbert infra-red spectrometer, which employs a plane grating and lead-sulphide photoconductive cell, was used on the Snow telescope at Mt. Wilson. The linear response of the cell enables a direct pen recording of infra-red intensities to be made: the tracings in this atlas are photo-offset reproductions of these recordings, reduced to five-eighths of the original scale. The shortest wave-length overlaps by $300 \mathrm{~A}$. the longer limit of the Utrecht (photographic). atlas, and by $5000 \mathrm{~A}$. the long-wave limit of the photographic work (not, however, yet reproduced as tracings) at Mt. Wilson.

The resolving power, which averages about 30,000 , is insufficient to reveal the true profiles of the narrower lines, but equivalent widths may be derived with fair accuracy by correcting for non-linearity and for scattered light. The light used was that of the centre of the sun observed near meridian passage in clear dry weather. Perhaps the least satisfactory feature of the atlas is the wave-length scale, (determined mainly by the method of overlapping orders), which is indicated by labelling minima only every $40 \mathrm{~A}$. or so along the traces; but even so, linear interpolation gives wave-lengths of intermediate features correct to about $\pm 0.1 \mathrm{~A}$. The atlas is a major work invaluable to astrophysicists, spectroscopists and meteorologists alike.

Fundamentals of Physical Chemistry

For Premedical Students. By Prof. H. D. Crockford and Prof. Samuel B. Knight. Pp. xi+366. (New York : John Wiley and Sons, Inc.; London : Chapman and Hall, Ltd., 1950.) 34s. net.

THE authors of this book are both professors of chemistry at the University of North Carolina. They have written for pre-medical and biological students on those sections of physical chemistry necessary for an understanding of medicine and biology. The emphasis is therefore on such items as solution, electrolytes, the conception of $p \mathrm{H}$, osmotic pressure, chemical equilibrium, buffer action, adsorption, the colloidal state and radioactivity. The only noticeable omission is the partition coefficient, a knowledge of which is helpful in the study of the action of anæsthetics. Knowing, as it were, the background of medical students, the authors have dispensed with the calculus; but the treatment with simple mathematics is quite thorough and is supported by numerous clearly worked out examples. In addition, there are ample sets of questions and numerical problems. The various concepts are expounded with unusual clearness, the subject-matter is up to date and the illustrative examples are appropriate and attractive. I believe that many will welcome and approve of the innovation (Chapter 7) of considering the direction of flow of the electrons as the direction of the flow of the current. Despite the title, this is a good and reliable introduction to physical chemistry for any type of student.

G. FowLES

\section{Corrosion Guide}

By Erich Rabald. Pp. vii +629. (New York and Amsterdam : Elsevier Publishing Co., Inc. ; London : Cleaver-Hume Press, Ltd., 1951.) 90s.

7 HIS book has forty-five pages on general principles, followed by more than five hundred pages of tables summarizing experience of various materials in numerous environments. What value the book has lies in the tables: the general sections will tell the corrosion specialist nothing he does not know already and a good deal he has (rightly) forgotten, while by their diffuseness they will tend to confuse the non-specialist.

In the tables, four categories of corrosion resistance of materials to environments are distinguished, based where possible on practical experience, and otherwise on laboratory determinations of weight-loss per unit area per unit time. Few indications of liability to pitting, intergranular corrosion or stress corrosion are given-a serious limitation in a book addressed to chemical engineers.

Perhaps the best test of a guide is that of use. While considering this review, I had occasion to seek data on the resistance of zinc to oxalic acid solutions, and that of several metals to nitrite solutions, but found the book silent on these matters. In betterknown fields, such as the behaviour of metals with ammonium sulphate solutions and with sea water, the book provides some accurate, but also some misleading, information (very little about sea water). No information is to be found on galvanized iror 